\title{
FETAL DEPTH AND ULTRASOUND PATH LENGTHS THROUGH OVERLYING TISSUES
}

\author{
Paul L. Carson, Jonathan M. Rubin and Edward H. Chiang \\ University of Michigan Medical Center, Ann Arbor, MI 48109-0553
}

\author{
(Received 8 June 1988; in final form 20 March 1989)
}

\begin{abstract}
Measurements of minimum thicknesses, in a four-layer, overlying tissue model, on 22 pregnancies between 15 and 20 weeks gestation, yielded a global minimum and a mean of the minimum total thickness per patient of 1.7 and $2.9 \mathrm{~cm}$, respectively, and a minimum and mean subcutaneous fat thickness of 0.7 and $1.4 \mathrm{~cm}$. Conservative calculations of the minimum attenuation per patient, at $3.5 \mathrm{MHz}$ indicated that less than $2.5 \%$ of 15 to 20 week pregnancies should fall below the lower $95 \%$ prediction line of: Attenuation (dB) $=0.10 \times$ Maternal Weight (kg) - 3.0. The smallest calculated attenuation for any of the 21 subjects was $0.8 \mathrm{~dB} \mathrm{MHz}^{-1}$ indicating just under a factor of two protection at $3.5 \mathrm{MHz}$ of proximal fetal tissues compared with ultrasound intensities measured in water. This value is lower than those generally used in the past. The knowledge of distributions of transducer-to-fetal distances and thicknesses of overlying tissues is also important for improvement of image quality. Measurement of minimum depth of the anterior fetal thorax in 57 examinations of 25 to 40 week fetuses yielded minimum and mean values of 2.5 and $4.1 \mathrm{~cm}$, respectively.
\end{abstract}

Key Words: Ultrasonic scanning, Ultrasonics, Ultrasonic diagnosis and anatomy, Dosimetry, Ultrasonic tissue characterization, Ultrasonic tissue effects, Effects of ultrasonic irradiation on fetus, Pregnancy, Ultrasonic attenuation, Maternal anatomy, Fetal monitoring, Image enhancement, Ultrasonic Doppler, Adverse effects, Second trimester.

\section{INTRODUCTION}

This work was undertaken to estimate and to facilitate future estimations of the ultrasound exposure to the fetus in the worst cases, those in which there is minimum ultrasound attenuation by intervening tissues. Identification of a worst case, or a small group of potentially high exposure situations, is necessary for the optimal design of ultrasound equipment that is free of significant risk to the fetus. Appropriate measurements in these cases allow calculation of estimated in situ intensities for comparison with actual measurements and even with results of ultrasound bioeffects and hyperthermia studies. Other types of examinations, for example, intraoperative imaging with a saline or water standoff, provide even less attenuation by tissues proximal to the focal point. However, obstetrical applications are more numerous and probably warrant greater attention.

The knowledge of distributions of distances to

Address reprint requests to: Paul L. Carson, Ph.D., University of Michigan Hospitals, Department of Radiology, Kresge III, Ann Arbor, MI 48109-0553. the fetus from the transducer and of thicknesses of various overlying tissue layers is as important for potential improvements in image quality as it is for exposure estimates. Ultrasound rays are refracted as they pass at any nonperpendicular angle between two layers of differing speeds. Then, even flat layers of subcutaneous fat can cause an error in sector scanner measurements of lateral distance, for example in femur length measurements. The thickness of fat layers determines the degree of effect on the focusing of all scanners.

Several earlier efforts at estimating attenuation in tissues overlying the fetus centered on first trimester pregnancy. They have been summarized by Stewart and Stratmeyer (1982) and the NCRP (1983). Those measurements yielded transducer-to-gestational sac attenuations (in decibels) ranging from $f_{o}$ to $7 f_{o}$, where $f_{o}$ is the ultrasound frequency (in $\mathrm{MHz}$ ). Those measurements generally used relatively large, phase sensitive ultrasound receivers to monitor the acoustic pressure in the uterus or the pressure decrease in reflections from a steel sphere in the uterus. Such phase sensitive techniques might be expected to over estimate the minimum attenuation to the fetus 
as illustrated by the following example. A lump of fat on one side of an ultrasound beam can delay the wavefront and cause it to arrive at one side of a typical (phase sensitive) transducer, at a different time (out of phase) compared with the wavefront incident on the other side of the transducer. Therefore, the early experiments on attenuation of sound in reaching the fetus should be repeated with phase insensitive methods, including a careful search for the peak or average in the beam. Calculations for the same anatomical situation in early gestation have ranged from a maximum of $23 \mathrm{~dB}$ at $2.5 \mathrm{MHz}$, using older, phase sensitive attenuation data (Hall 1975), to 4.1 $\mathrm{dB}$ at $3.5 \mathrm{MHz}$ using phase insensitive attenuation data (NCRP 1983). In vitro measurements of temperature during exposure have been made recently, but the exposure conditions were not those which might produce the highest anticipated temperature rises and none were detected (Soothill et al. 1987).

Recent measurements of ultrasound attenuation in the abdominal wall and organs proximal to points in the liver and kidney have been performed on fixed sections from two cadavers (Smith et al. 1985). Good agreement was obtained between in situ measurements and a layered tissue model similar to that employed here. Attenuation coefficients used in that model were those measured in tissue samples from the cadavers.

Models of ultrasound attenuation proximal to the fetus may be subdivided into each of the trimesters. Attenuation estimates in the first and last trimester were suggested by Carson (1988), based on an informal search of worst cases in a few clinical examinations. As detailed in Table 1 , these estimates yielded a total minimum attenuation at $3.5 \mathrm{MHz}$ of $3.9 \mathrm{~dB}$ in the first trimester and $1.6 \mathrm{~dB}$ in the third trimester, from overlying tissue of thicknesses of 2.6 and $1.0 \mathrm{~cm}$, respectively. These estimates, being less than earlier estimates and measurements, suggested a need for specific worst case measurements. Another recent estimate of minimum overlying tissue thickness was $1.25 \mathrm{~cm}$ for the third trimester, based on experience with a water path scanner (Kossoff 1988, private communication). One might expect the potential for damage from a given intensity in situ to be higher in early pregnancy than in near term, because damage to a single cell can be critical during organogenesis and because the fetus is believed to be more sensitive to hyperthermia in the early stages. The added attenuation in early pregnancy counterbalances that somewhat.

\section{METHODS}

The second trimester case was studied most extensively because of the limited information on this trimester, because of the expected fetal sensitivity to thermal and other insults at this stage and because the amount of overlying tissue was expected to be significantly thinner than in the first trimester. Ultrasound imaging for guidance of genetic amniocentesis provided a large set of patients in a limited range of gestational ages. Thicknesses of overlying tissues were measured in group A, consisting of 22 pregnancies between 15 and 20 weeks gestation. The mean gestational age and mean maternal weight were 16.6 weeks and $64.9 \mathrm{~kg}$, respectively. Subjects were selected randomly, independent of maternal size. In all cases, the study was approved by the appropriate institutional review board. Informed consent was obtained from the subjects, after the nature of the procedures had been fully explained.

The second trimester imaging was performed with a conventional sector scanner (Picker Artis. with

Table 1. Attenuation in previously-suggested worst case fetal exposures during the first and third trimesters. Assumed values for attenuation coefficients and tissue path lengths in the first trimester case are the same as Table 2.4 of NCRP Report 74 (NCRP, 1983) except only a $1 \mathrm{~cm}$ path length of fat is assumed here.

\begin{tabular}{|c|c|c|c|c|c|c|}
\hline \multirow[b]{2}{*}{ Tissue } & \multicolumn{2}{|c|}{ Attenuation coefficient } & \multicolumn{2}{|c|}{ First trimester } & \multicolumn{2}{|c|}{ Near term } \\
\hline & $\begin{array}{l}(\mathrm{Np} / \mathrm{cm}- \\
\mathrm{MHz})\end{array}$ & $\begin{array}{c}(\mathrm{dB} / \\
\mathrm{cm}-\mathrm{MHz})\end{array}$ & $\begin{array}{l}\text { Path length } \\
\qquad(\mathrm{cm})\end{array}$ & $\begin{array}{l}\text { Attenuation } \\
(\mathrm{dB} / \mathrm{MHz})\end{array}$ & $\begin{array}{l}\text { Path } \\
(\mathrm{cm})\end{array}$ & $\begin{array}{l}\text { Attenuation } \\
(\mathrm{dB} / \mathrm{MHz})\end{array}$ \\
\hline Fat & 0.053 & 0.46 & 1.0 & 0.46 & 0.3 & 0.14 \\
\hline $\begin{array}{l}\text { Muscle, skin \& } \\
\text { bladdert }\end{array}$ & 0.059 & 0.51 & 0.6 & 0.31 & 0.5 & 0.26 \\
\hline $\begin{array}{l}\text { Bladder \& \& uterine } \\
\text { muscle } \\
\text { Total attenuation }\end{array}$ & 0.039 & 0.34 & 1.0 & $\begin{array}{l}0.34 \\
1.11\end{array}$ & 0.2 & $\begin{array}{l}0.07 \\
0.47\end{array}$ \\
\hline $\begin{array}{l}\text { Attenuation at } 3.5 \\
\mathrm{MHz}\end{array}$ & & & $3.9 \mathrm{~dB}$ & & & $1.6 \mathrm{~dB}$ \\
\hline
\end{tabular}

$\uparrow$ No path through the bladder wall is assumed in the near term example. 
a 5 or $3.5 \mathrm{MHz}$ transducer). Two to six images were recorded specifically to display the minimum thickness of tissues overlying the fetus and giving a good view thereof. To facilitate differentiation of the various surface layers, a standoff was employed, consisting of $250 \mathrm{ml}$ intravenous saline drip bags or $3 \mathrm{M}$ butadiene-styrene Flotation $\mathrm{Pad}^{\mathrm{TM}}$ material containing scatterers for increased attenuation.

In several cases, the sector scanner was used to record images of the same plane, with and without a standoff. The same plane was then imaged with a linear array. The minimum thickness of overlying tissue was measured for each condition. Measurements with the standoff pad and the linear array agreed within $\pm 1 \mathrm{~mm}$, while direct contact sector scanning depressed the thickness of overlying tissues by an average of $3 \mathrm{~mm}$ more than the other two methods. Calipers were used and compared with vertical distance markers on the side. These distance markers had been calibrated with a tissue-mimicking test object as having less than $\mathrm{a} \pm 1 \%$ inaccuracy. Tissues were grouped into the categories listed in the caption to Fig. 1 because those layers could be distinguished or estimated and because of the known differences in attenuation coefficients (or expected differences in future measurements). The placenta is not included because it will not, in the worst cases, lie in the imaging path proximal to the fetus. Typical anatomy is illustrated in the ultrasound image of Fig. 2 for a 15 week pregnancy.

Groups B and C, consisting of 227 and 57 examinations, respectively, were analyzed for the minimum maternal skin to anterior fetal thorax distance. This minimum distance to the anterior fetal thorax (referred to subsequently as minimum fetal thorax depth) was acquired initially for data quality assurance in a larger study. These two groups covered presumably normal pregnancies between 25 and 40 weeks gestation and were performed with a mechanical sector scanner (ATL Mark 100, 3.5 and $5 \mathrm{MHz}$, $13 \mathrm{~mm}$ diameter transducers), without standoffs. In group B, a single image was acquired at the end of the examination, with a modest effort made to make that image reveal the minimum ultrasound path length to the anterior fetal thorax. The ultrasonographer then measured the minimum fetal thorax depth in that image. To compare those minimum depths per image with a value closer to minimum depth per examination, the 57 subjects in Group $C$ were studied in exactly the same manner as Group B, except that all of approximately 25 images acquired on a subject were analyzed for the overall minimum fetal thorax depth, as well as for minimum depth in the last image. The mean gestational age and maternal weight were 31.9

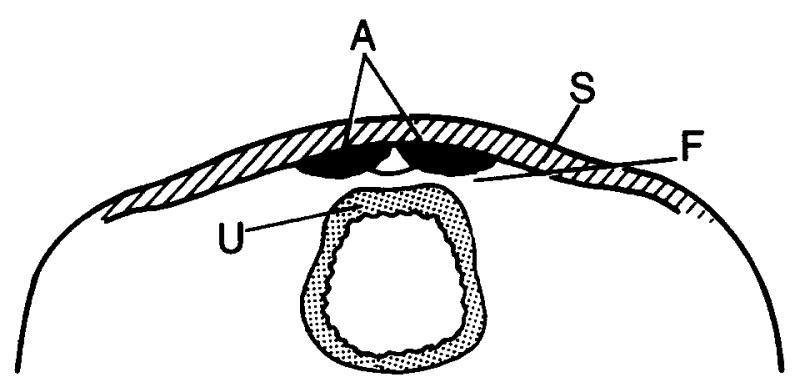

(a)

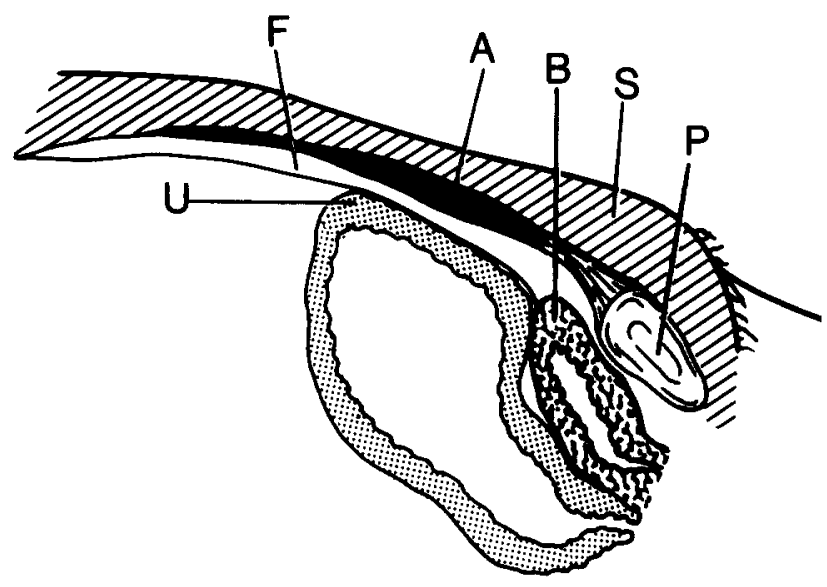

(b)

Fig. 1. (a) Anatomical model for second trimester pregnancy as used in Model F2. Transverse view. (b) Sagittal view. For attenuation calculations, layer boundaries are assumed to be normal to the ultrasound scan. Anatomical tissue layers are as follows. Layers $\mathrm{A}$ and $\mathrm{F}$ are combined in the measurements. S-skin and subcutaneous fat; $\mathrm{A}-\mathrm{ab}$ dominal muscle or linea alba; $\mathrm{F}$ - fatty fascia (preperitoneal

fat); U-myometrium; P-pubic bone; B-Bladder.

weeks and $72.8 \mathrm{~kg}$, respectively, for Group B and 32.3 weeks and $69.8 \mathrm{~kg}$ for Group C.

Except for skin, attenuation coefficients used to calculate attenuation in the various tissue layers of Group A were the same as those employed previously (NCRP 1983, p. 380; Carson 1988). In $\mathrm{dB} \mathrm{cm}^{-1}$ $\mathrm{MHz}^{-1}$, they were:

skin-1.5

subcutaneous fat -0.46

abdominal (skeletal) muscle and preperitoneal

fascia -0.51

myometrium (smooth muscle) -0.29

These estimates are at or slightly lower than the best measured values in vitro (NCRP 1983, p. 28). The attenuation coefficient for skeletal muscle is slightly lower than the phase insensitive measurement of $0.55 \mathrm{~dB} \mathrm{~cm}^{-1}$, made on bovine gluteal muscle. In the absence of measurements, for preperito- 


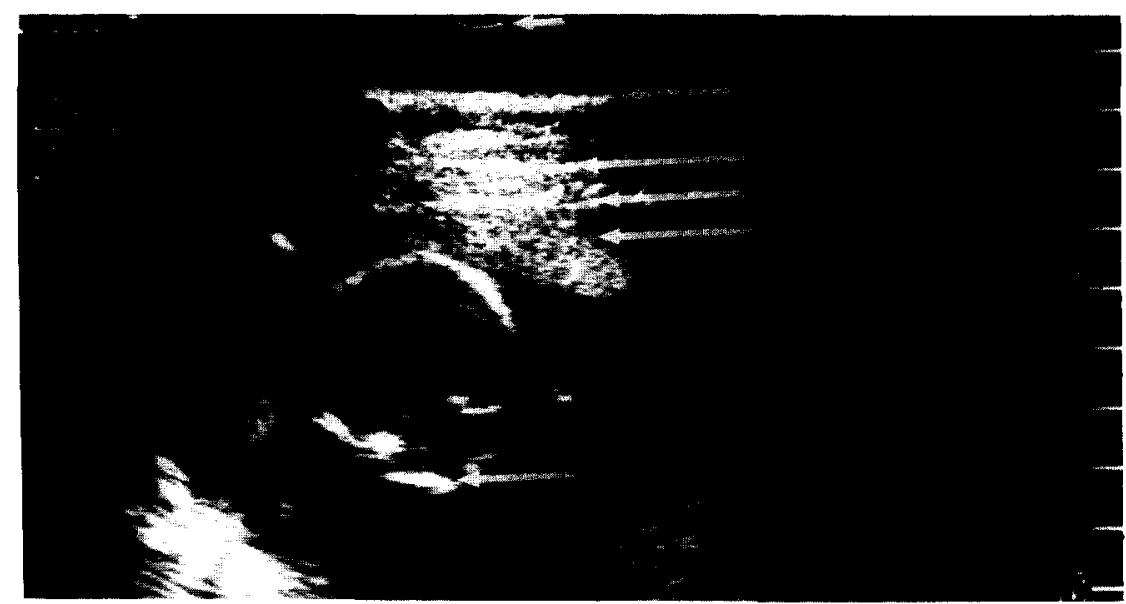

Fig. 2. Typical anatomy for the tissue model. Between each pair of arrows from the top are the standoff, skin and subcutaneous fat combined, abdominal muscle and fatty fascia combined and the myometrium. The fetal head is below the myometrium, with a small segment of placenta on the right. The abdominal wall layers are usually visualized more clearly with a linear array.

neal fascia, the same value was taken as for skeletal muscle. These two layers were initially separated in our initial thickness, but they could not be discriminated reliably and were combined. The value for subcutaneous fat is approximately midway within the phase sensitive range for breast tissue (NCRP 1983). The myometrium value is in the phase sensitive range of 0.23 to $1.9 \mathrm{~dB} \mathrm{~cm}^{-1} \mathrm{MHz}^{-1}$ for smooth muscle (NCRP 1983). For skin, the mean and minimum thicknesses used were based on Dines et al. (1984) and ICRP (1975) and the attenuation coefficient was based on Nakaima et al. (1976) and Pohlhammer and O'Brien (1980).

Attenuation in body fluids and attenuation due to reflections at the identified layer boundaries were negligible in this perpendicular layered model (NCRP 1983; Carson 1988; Smith et al. 1985), and were not included.

\section{RESULTS}

In the measurements to determine the differences in abdominal wall compression by different transducer contact methods, abdominal wall thickness was measured at a total of 22 locations with thicknesses between 8 and $38 \mathrm{~mm}$ in the 14 subjects. The sector scanner depressed the abdominal wall such that the mean abdominal wall thickness was less than with the standoff by $3.5 \pm 0.2 \mathrm{~mm}$ standard error of the mean (SEM). In this sample, mean abdominal wall thickness with the standoff was 20.0 $\pm 1.4 \mathrm{~mm}$ SEM. Wall thickness measurements with the linear array in direct contact were only $1.2 \pm 0.3$ $\mathrm{mm}$ less than these with the standoff. With both the linear array and sector scanner, in this limited sample, there was no correlation between the amount of abdominal wall compression and the abdominal wall thickness, maternal weight, or gestational age. All thicknesses of overlying tissues are reported as measured with the standoff.

Figure 3 shows individual measurements of thicknesses of overlying tissue layers and total overlying tissue thicknesses in the second trimester group, Group A, as a function of maternal weight. Linear regressions covering all subjects up to a maternal weight of $82 \mathrm{~kg}$ are shown as the solid lines. Gestational age was included in a multivariate linear regression, but did not increase the correlation coefficient in this sample, taken over a relatively short range of gestational age. The one case at $97 \mathrm{~kg}$ was not included in the linear regressions, because the data suggested that different anatomical structure may be present in this obese case, and the relationships may, indeed, be particularly nonlinear above a certain body weight. Perhaps the tissues were so flexible that they could be moved to the side or could be displaced more readily by the transducer. This suggests caution in applying these results to individuals above $82 \mathrm{~kg}$.

Coefficients of the linear regressions for tissue thickness are given in Table 2, along with the 95\% confidence limits for the equation:

$$
\begin{aligned}
\text { Thickness }(\mathrm{cm})= & \text { Weight Coefficient } \\
& \times \text { Weight }(\mathrm{kg})+\text { Constant }(\mathrm{cm}) .
\end{aligned}
$$



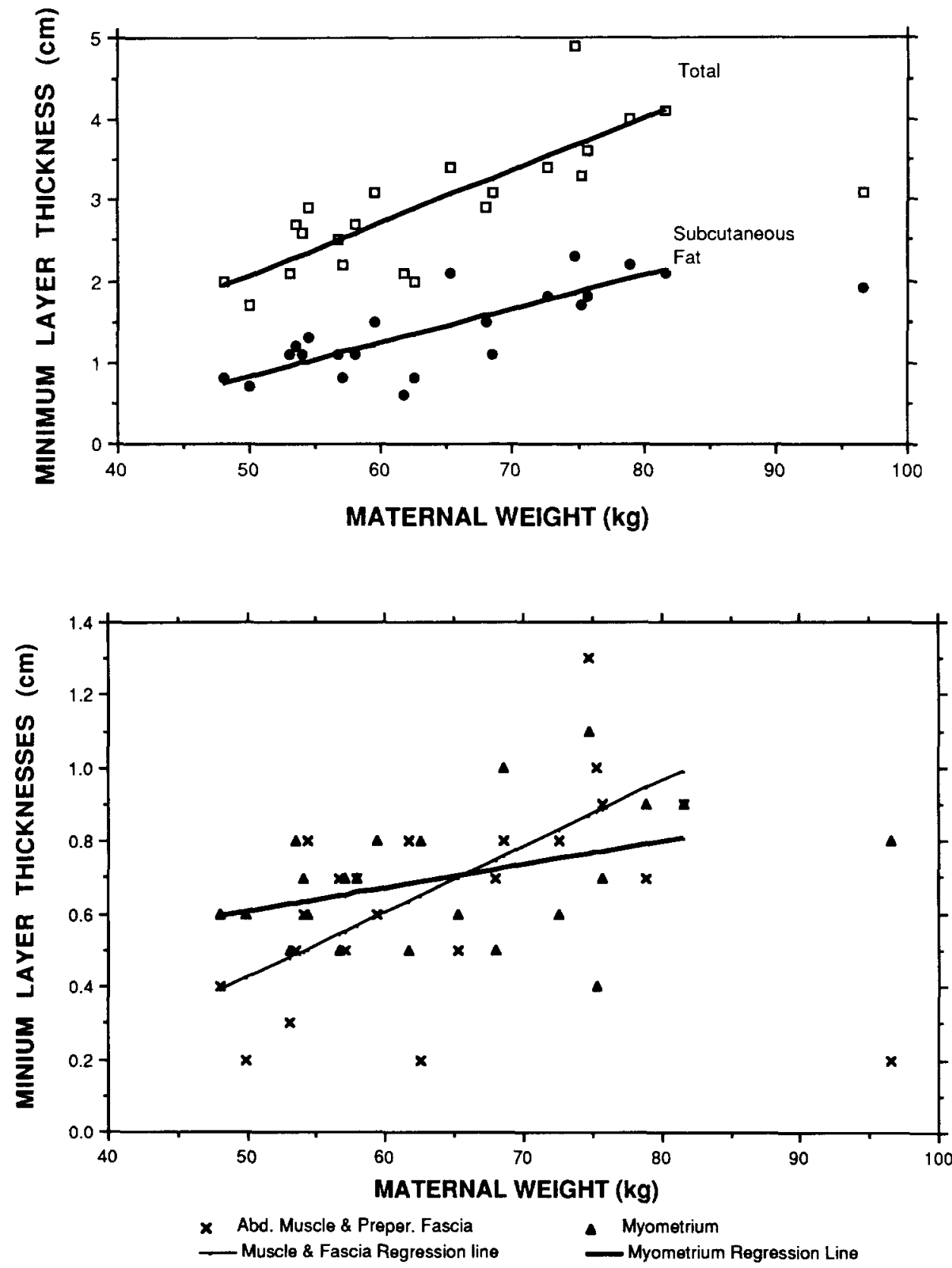

Fig. 3. For the 21 subjects examined from 15 to 20 weeks gestation, thicknesses are shown as a function of maternal weight for the three tissue layers, excluding skin, which are always overlying the fetus. The three individual thicknesses and their total thickness, including $2 \mathrm{~mm}$ for skin, were measured along the line offering the minimum soft tissue path length to the fetus, as well as a good view of the fetus, in a typical amniocentesis procedure. Linear regressions are shown as solid lines.

The probability that the regression relation between layer thicknesses and maternal weight could result from random fluctuations is given in Table 2, as calculated by the $F$-test (Gardner 1987). It is clear that the relations with maternal weight are less significant for abdominal muscle thickness and myometrium than fat, as might be expected. The $95 \%$ confi- dence limits show the $95 \%$ confidence range for the regression line. A different type of limit is required to indicate the range of minimum tissue layer thicknesses into which $95 \%$ of all future individual measurements are predicted to fall, using the same patient population and methods. The $95 \%$ prediction limits in Table 2 give such a range (Sokal and Rohlf 1981), 
Table 2. Linear regressions of minimum thickness of tissue layers overlying the fetus.

\begin{tabular}{|c|c|c|c|c|}
\hline $\begin{array}{c}\text { Regression coefficients } \\
\text { of thicknesses }(\mathrm{cm})\end{array}$ & $\begin{array}{l}\text { Maternal weight } \\
\text { coefficient } \\
(\mathrm{cm} / \mathrm{kg})\end{array}$ & Constant $(\mathrm{cm})$ & $\begin{array}{c}\text { Coefficients } \\
\text { determination } \\
\mathrm{R}^{2}\end{array}$ & $\begin{array}{l}\text { Probability } \\
\text { relation is } \\
\text { random }\end{array}$ \\
\hline $\begin{array}{l}\text { Total } \\
\text { [95\% conf. lim.] } \\
\text { (95\% pred. lim.) }\end{array}$ & $\begin{array}{l}0.065 \\
{[0.087,0.043]} \\
(0.066,0.064)\end{array}$ & $\begin{array}{l}-1.2 \\
{[0.18,-2.6]} \\
(-0.22,-2.2)\end{array}$ & 0.67 & $<0.001$ \\
\hline $\begin{array}{l}\text { Subcutaneous fat } \\
\text { [95\% conf. lim.] } \\
\text { (95\% pred. lim.) }\end{array}$ & $\begin{array}{l}0.041 \\
{[0.056,0.026]} \\
(0.040,0.041)\end{array}$ & $\begin{array}{l}-1.2 \\
{[-0.24,-2.2]} \\
(-0.52,-1.9)\end{array}$ & 0.62 & $<0.001$ \\
\hline $\begin{array}{l}\text { Abdominal muscle and } \\
\text { preperitoneal } \\
\text { fascia } \\
\text { [95\% conf. lim.] } \\
\text { (95\% pred. lim.) }\end{array}$ & $\begin{array}{l}0.018 \\
{[0.028,0.009]} \\
(0.018,0.018)\end{array}$ & $\begin{array}{l}-0.47 \\
{[0.12,-1.0]} \\
(-0.05,-0.90)\end{array}$ & 0.46 & $<0.001$ \\
\hline $\begin{array}{l}\text { Myometrium } \\
\text { [95\% conf. lim.] } \\
\text { (95\% pred. lim.) }\end{array}$ & $\begin{array}{l}0.006 \\
{[0.014,-0.002]} \\
(0.007,0.006)\end{array}$ & $\begin{array}{l}0.28 \\
{[0.80,-0.23]} \\
(0.65,-0.08)\end{array}$ & 0.13 & $<0.12$ \\
\hline
\end{tabular}

Regression coefficients are accompanied by upper and lower $95 \%$ confidence limits for the regression coefficients [in brackets] and linearized $95 \%$ prediction limits for individual points (in parentheses).

assuming a normal distribution. Thus, one can calculate, for example that $95 \%$ of $68 \mathrm{~kg}$ pregnant women would be expected to exhibit minimum subcutaneous fat layers over fetuses in this age group of 0.9 to $2.2 \mathrm{~cm}$.

As shown in Table 3, the minimum path length of attenuating tissue found was only $1.7 \mathrm{~cm}$, corresponding to a calculated attenuation of $0.8 \mathrm{~dB} / \mathrm{MHz}$ or $2.8 \mathrm{~dB}(48 \%)$ at $3.5 \mathrm{MHz}$. Skin thickness in this minimum thickness case was assumed to be $1.3 \mathrm{~mm}$, compared with the average $2 \mathrm{~mm}$ assumed elsewhere. This subject was not a rare exception, merely the least in a rather broad distribution for the 22 subjects, with a mean path length of $2.9 \mathrm{~cm}$ and a standard deviation of the sample of $0.8 \mathrm{~cm}$. There were five subjects with a measured path length from 2 to $2.2 \mathrm{~cm}$.

Figure 4 shows the calculated minimum attenuations at $3.5 \mathrm{MHz}$ for individuals as a function of maternal weight at the time of examination. Calculated attenuation correlated reasonably well with maternal weight $\left(R^{2}=0.68\right)$, and the latter might be used in some cases to estimate the former. The best fit linear regression to the data is shown in Fig. 4 as the bold line, given by:

Table 3. Minimum measured thickness and estimated attenuation of intervening soft tissues in 22 pregnancies between 15 and 20 weeks gestation.

\begin{tabular}{|c|c|c|c|c|c|c|c|c|}
\hline & Skin & $\begin{array}{c}\text { Subcut. } \\
\text { fat }\end{array}$ & $\begin{array}{c}\text { Abdominal } \\
\text { muscle and } \\
\text { preperitoneal }\end{array}$ & Myometrium & Total & $\begin{array}{l}\text { Gestation } \\
\text { age (wk) }\end{array}$ & $\begin{array}{c}\text { Weight } \\
(\mathrm{kg})\end{array}$ & $\begin{array}{l}\text { Abdominal } \\
\text { thickness } \\
\text { (cm) }\end{array}$ \\
\hline \multicolumn{9}{|l|}{ Thickness $(\mathrm{cm})$} \\
\hline Mean & 0.2 & 1.4 & 0.6 & 0.7 & 2.9 & 16.5 & 65 & 19.3 \\
\hline Minimum & 0.13 & 0.7 & 0.2 & 0.6 & 1.7 & 15 & 50 & 17 \\
\hline$S D$ & 0.0 & 0.5 & 0.3 & 0.2 & 0.8 & & 12 & \\
\hline $\begin{array}{l}\text { Assumed attenuati } \\
\text { coefficient (dB } \\
\left.\mathrm{cm}^{-1} \mathrm{MHz}^{-1}\right)\end{array}$ & 1.5 & 0.46 & 0.51 & 0.29 & & & & \\
\hline \multicolumn{9}{|l|}{$\begin{array}{l}\text { Estimated } \\
\text { attenuation at } \\
3.5 \mathrm{MHz}(\mathrm{dB})\end{array}$} \\
\hline Mean & 1.1 & 2.3 & 1.1 & 0.7 & 5.2 & & & \\
\hline Minimum & 0.7 & 1.1 & 0.4 & 0.6 & 2.8 & & & \\
\hline
\end{tabular}

Placenta is not included because it would not be there in the worst case. The amniotic fluid path may be adjusted to achieve the worst case for each transducer focal zone. 


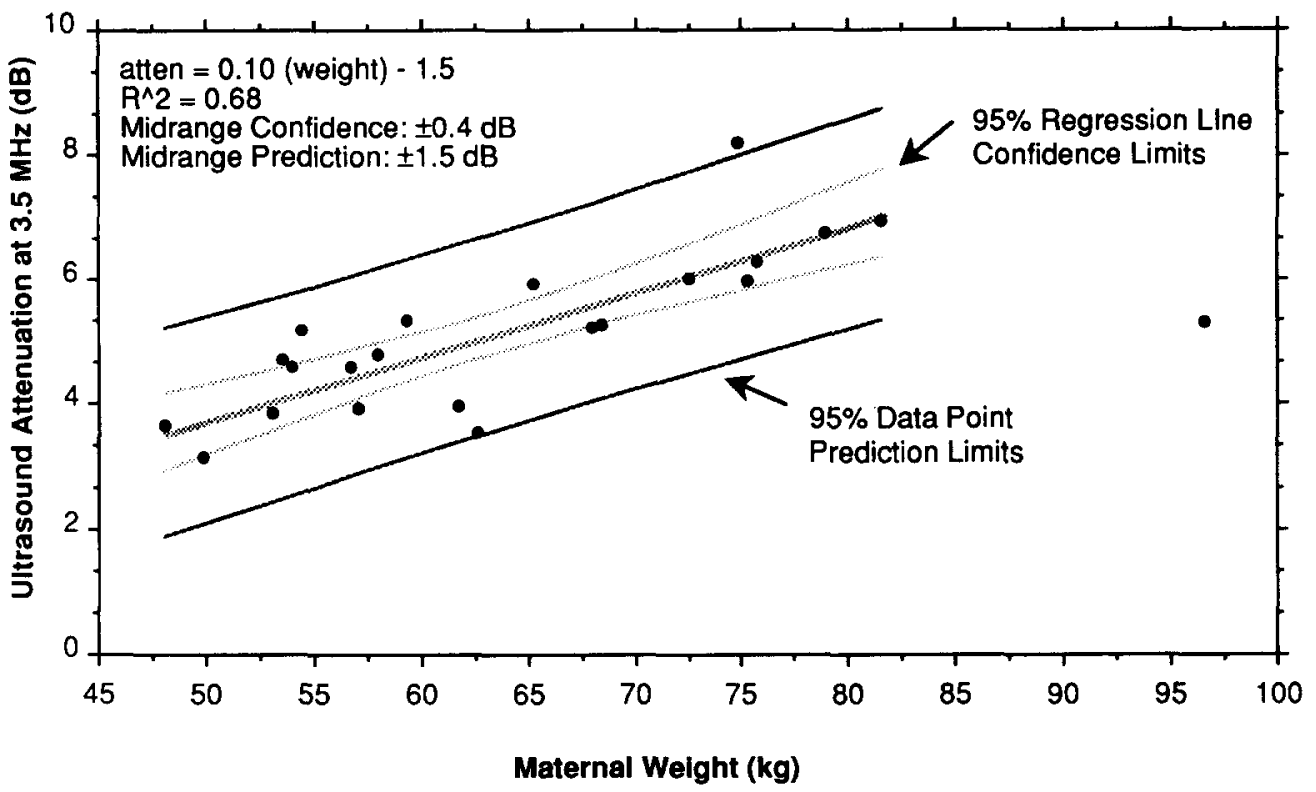

Fig. 4. Attenuations by overlying tissues are shown as a function of maternal weight for gestational ages of 15 to 20 weeks. The attenuations are calculated from measured minimum tissue layer thicknesses on each subject, using phase-insensitive attenuation coefficients.

Attenuation $(\mathrm{dB})=0.10 \times$ Weight $(\mathrm{kg})-1.5$.

The 95\% limits for attenuation in individual patients are also plotted in Fig. 4. With the lower prediction limit given approximately by:

$$
\text { Attenuation }=0.10 \times \text { Maternal Weight }-3.0 \text {. }
$$

Attenuation correlated almost as well $\left(R^{2}=0.57\right)$ with maternal anterior-posterior diameter as:

$$
\text { Attenuation }=0.39 \times \text { Thickness }(\mathrm{cm})-2.3 \text {. }
$$

Among the set of minimum recorded distances of ultrasound travel from the skin to the fetus in the 15 to 20 week group, Group A, the minimum and mean distances (depths) were 2.5 and, $4.1 \mathrm{~cm}$, respectively. Regression coefficients, their $95 \%$ confidence limits and the $95 \%$ prediction limits are given in Table 4 . With fetal depth, as well as with overlying tissue thicknesses, the correlation with gestational age was not significant. In fact, fetal depth in this sample was rather widely distributed, so there is a modest probability, $<0.03$, that the correlation with maternal weight was due to chance.

Also given in Table 4 are regression coefficients and statistical data for minimum distances from the maternal skin to the fetal thorax in groups B and C. Regressions for group $\mathrm{C}$ are given both for the reading of all images of a study and for reading only of the last image acquired. Minimum depth readings from a single film were more varied and larger than the minimum determined from approximately $10 \mathrm{films}$, with confidence limits of the former twice as large as those of the latter. At group C's mean gestational age of $32.3 \mathrm{wk}$ and maternal weight of $69.8 \mathrm{~kg}$ the regression fit values for fetal thorax depths in single and multiple films were $3.8 \mathrm{~cm}$ and $3.1 \mathrm{~cm}$, respectively. At that same gestational age and maternal weight in the larger group, B, the regression fit fetal thorax depth was $3.7 \mathrm{~cm}$, and the minimum was $1.5 \mathrm{~cm}$. The distance to the fetal thorax decreased modestly as a function of gestational age and increased with maternal weight in group B and in both analyses of group $C$, but these changes were not large in view of the $95 \%$ confidence limits. Despite the low coefficients of determination, the probability by $F$ test was generally low that the relation between fetal depth and gestational age and maternal weight was random. That probability was less than 0.001 in the largest group B, despite use of the more variable method of reading only the last film. The only exception was in the smaller Group C, using only the last image, where there was a large, 0.7 , probability of a purely random relation. That data was included only to illustrate the need for an extensive search to find the minimum fetal thorax depth.

To illustrate the distribution of fetal depth data from the third trimester, Fig. 5 shows the distribution of minimum distances from the maternal skin to the 
Table 4. Linear regressions of minimum fetal to maternal skin distance in three populations.

\begin{tabular}{|c|c|c|c|c|c|}
\hline $\begin{array}{c}\text { Regression coefficients } \\
\text { of fetus to skin } \\
\text { distances }(\mathrm{cm})\end{array}$ & $\begin{array}{c}\text { Maternal weight } \\
\text { coefficient } \\
(\mathrm{cm} / \mathrm{kg}) \\
\end{array}$ & $\begin{array}{c}\text { Gestational age } \\
\text { coefficient } \\
(\mathrm{cm} / \mathrm{wk}) \\
\end{array}$ & $\begin{array}{c}\text { Constant } \\
(\mathrm{cm})\end{array}$ & $\begin{array}{l}\text { Coefficient } \\
\text { of deter. } \\
\text { R2 }\end{array}$ & $\begin{array}{c}\text { Probability } \\
\text { relation is } \\
\text { random }\end{array}$ \\
\hline $\begin{array}{l}21 \text { Subjects; } 15-20 \text { wks } \\
\text { [95\% conf. lim.] } \\
\text { (95\% pred. lim.) }\end{array}$ & $\begin{array}{l}0.044 \\
{[0.082,0.006]} \\
(0.044,0.044)\end{array}$ & & $\begin{array}{l}1.3 \\
{[2.7,-0.1]} \\
(3.1,-0.6)\end{array}$ & 0.23 & $<0.03$ \\
\hline $\begin{array}{l}227 \text { Subjects, } 25-40 \\
\text { wks } \\
\text { Min. from last image } \\
\text { [95\% conf. lim.] } \\
\text { (95\% pred. lim.) }\end{array}$ & $\begin{array}{l}0.027 \\
{[0.050,0.014]} \\
(0.027,0.027)\end{array}$ & $\begin{array}{l}-0.035 \\
{[-0.006,-0.076]} \\
(-0.035,-0.035)\end{array}$ & $\begin{array}{l}2.9 \\
{[5.6,0.2]} \\
(5.1,0.6)\end{array}$ & 0.07 & $<0.001$ \\
\hline $\begin{array}{l}57 \text { Subjects; } 25-40 \text { wks } \\
\text { Min. from all images } \\
\text { [95\% conf. lim.] } \\
\text { (95\% pred. lim.) }\end{array}$ & $\begin{array}{l}0.017 \\
{[0.037,-0.003]} \\
(0.018,0.016)\end{array}$ & $\begin{array}{l}-0.053 \\
{[-0.002,-0.104]} \\
(-0.054,-0.052)\end{array}$ & $\begin{array}{l}3.6 \\
{[6.2,1.0]} \\
(5.0,2.2)\end{array}$ & 0.11 & $<0.04$ \\
\hline $\begin{array}{l}57 \text { Subjects; } 25-40 \text { wks } \\
\text { Min. from last image } \\
\text { [95\% conf. lim.] } \\
\text { (95\% pred. lim.) }\end{array}$ & $\begin{array}{l}0.015 \\
{[0.055,-0.025]} \\
(0.017,0.013)\end{array}$ & $\begin{array}{l}-0.024 \\
{[-0.076,-0.124]} \\
(-0.027,-0.023)\end{array}$ & $\begin{array}{l}3.5 \\
{[8.5,-1.5]} \\
(6.3,0.7)\end{array}$ & 0.01 & $<0.7$ \\
\hline
\end{tabular}

95\% confidence limits [in brackets] are given with each coefficient and linearized, $95 \%$ limits for prediction of individual minimum depths are presented (in parentheses).

anterior fetal thorax as measured from the multiple images in each case of Group C; regression and limit lines shown were calculated as a function of maternal weight only.

\section{DISCUSSION AND CONCLUSIONS}

Other studies have assumed that the worst case exposure in early pregnancy would be when the ul- trasound beam passes through the distended bladder. Even before 15 weeks gestation, however, the bladder path is not necessary. Amniotic fluid can provide an equivalent, minimally attenuating path without the added attenuation of the bladder wall. Indeed, minimum ultrasound path lengths through tissue are significantly less in the 15-20 week range than in earlier estimates of 1st trimester exposures. Furthermore, it is not absolutely clear that the fetus is most sensitive

MINIMUM FETAL THORAX DEPTH vs. MATERNAL WEIGHT

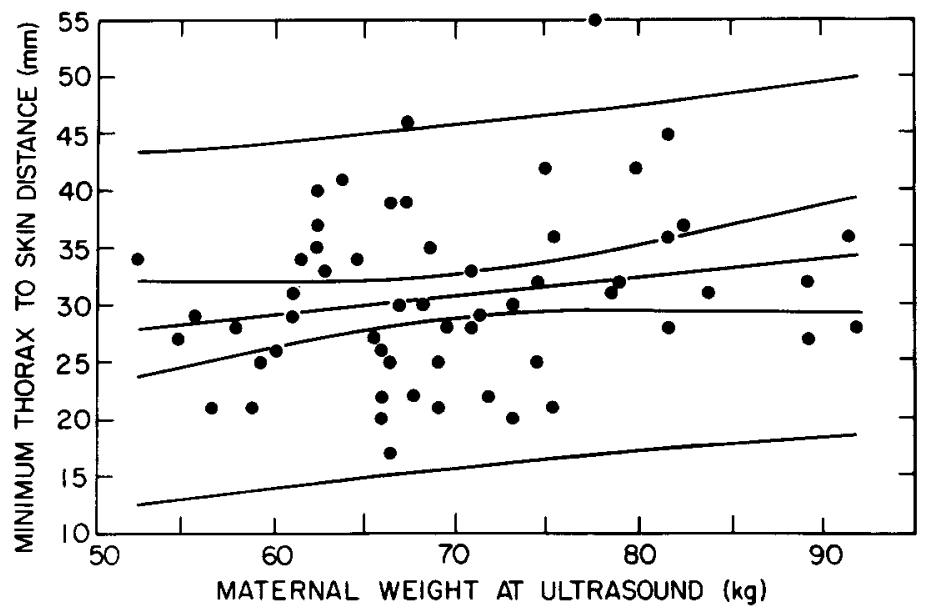

Fig. 5. Minimum fetal anterior thorax depths, recorded in any of the images of each of 57 subjects, are plotted as a function of maternal weight. There is also a dependence of depth on gestational age over this 25 to 40 week range. Ninety-five percent confidence limits on the regression line and $95 \%$ prediction limits for future individual data points are drawn as in Fig. 4. 
to ultrasound in the first trimester. Heating effects might be most pronounced in the second trimester near well ossified bone, with its strong ultrasound absorption.

These measurements of tissue thicknesses do not replace in vivo dosimetry of true in situ intensities or temperature rise. They should however, compliment such measurements and extend their range of validity. Tissue thickness and fetal depth measurements like these could be made at the time of dosimetry measurements and the attenuation used to verify or adjust these or similar measurements and calculations. It is unlikely, and perhaps inappropriate, that in vivo dosimetry will be performed on a large number of cases as a function of maternal weight and gestational age.

There are several features of these attenuation calculations which might be providing misleading results, although the major effects probably are in opposite directions. Thicknesses of overlying tissues, as measured with a flexible standoff pad, were not corrected for the slightly greater compression of subcutaneous tissues in contact scanning with linear arrays or the significantly greater ( $3.5 \mathrm{~mm}$ greater) mean compression normally experienced with a sector scanner. With a contact sector scanner, attenuation by overlying tissues might well be slightly less than what is reported here. Assuming the subcutaneous fat is compressed $0.35 \mathrm{~cm}$ at $0.46 \mathrm{~dB} / \mathrm{cm}$, total attenuation, calculated at $3.5 \mathrm{MHz}$ in the mean case of Table 3, would be reduced from 4.6 to $3.9 \mathrm{~dB}$.

Among the factors that might indicate higher sound attenuation than we have calculated is the fact that the phase insensitive attenuation coefficients assumed were usually measured with a radiation force technique, which would be insensitive to spreading of a highly focused beam by heterogeneous tissues. Attenuation of the spatial-peak intensities might be considerably higher, although attenuation of the total beam power would be unaffected by beam spreading. Furthermore, the attenuation coefficient of the fatty fascia, a heterogeneous mixture of fat and fibrous tissue, has not been measured extensively. Attenuation coefficients increase slightly more strongly with frequency than linearly, particularly for fat.

A similar attenuation analysis was performed on 28 sonograms taken from the general literature (Smith et al. 1985). Although almost the same attenuation coefficients were utilized for their obstetrical example as in the above models, the calculated total attenuations were much higher. The mean attenuations varied approximately linearly from $12 \mathrm{~dB}$ at 6 weeks gestation to $10 \mathrm{~dB}$ at 35 weeks. The standard deviation of the attenuations was surprisingly low. A plausible explanation for those much higher attenuation values is that, attenuation by the placenta was included and, unlike our study, the images taken from the literature had been obtained with no effort to locate a path of minimum attenuation. The results of Smith et al. (1985), represented something closer to the average attenuation paths in average images, whereas our study attempted to find minimum attenuation paths in each patient. It is interesting, however, that none of the 84 scan lines in 28 sonograms provided calculated attenuation paths near the smaller 2.8-4 dB values reported here.

The FDA calculations of in situ intensities for demonstration of equipment equivalence with pre-1976 devices, utilize what was thought to be a conservative attenuation coefficient of $0.3 \mathrm{~dB} \mathrm{~cm}^{-1}$ $\mathrm{MHz}^{-1}$ in a homogeneous tissue model. The model is not conservative in comparison with the present measurements and calculations. In a typical case of 3.5 $\mathrm{MHz}$ frequency and $7 \mathrm{~cm}$ focal length, the FDA model indicates an ultrasound attenuation of $7.4 \mathrm{~dB}$ or an intensity reduction by a factor of $1 / 5.5$, compared with the worst case measured here in the second trimester of only $2.8 \mathrm{~dB}$ or an intensity reduction by a factor of $1 / 1.9$.

Duck and Perkins (1988) reported similar abdominal wall thicknesses to those reported here for the case of scanning through the bladder to the gestational sac. In 74 randomly chosen obstetrical ultrasound scans they measured a least tissue thickness overlying the bladder of 0.7 to $6.0 \mathrm{~cm}$ with a mean of 2.1 and standard deviation of $0.8 \mathrm{~cm}$. Greatest bladder depth (presumably greatest distance to the distal internal border of the bladder) was 3.0 to $10.5 \mathrm{~cm}$ with a mean of $7.5 \mathrm{~cm}$.

Rather than viewing the data reported here as true minimum fetal depths, and overlying tissue layer thicknesses, readers should be mindful that the data represent the minimum quantities recorded under the conditions of these studies. As such, they probably are rather slight overestimates of minimum depths and thicknesses over the entire sample populations. In the fetal thorax depths of Fig. 5, there are no outliers with depths less than the $95 \%$ prediction limits. The same was true, and more notable, in the larger Group B.

In Group B, 10 of the 227 cases had fetal thorax depths greater than the $95 \%$ prediction limits. These skewed distributions with more outliers to the side of greater depths is to be expected with the less than exhaustive screening for true minimum depth and the anatomical limitation that the thorax cannot be any closer to the skin than the wall of the uterus, which can be in contact with the maternal abdominal 
wall. While the distribution is somewhat skewed, the statistics employed here, based on the assumption of gaussian distributions are conservative and adequately representative for the purpose of this study.

The data show a surprising uniformity in minimum fetal depths during the second and third trimesters studied. This uniformity and the relatively shallow depths help explain what, to us, has been a surprisingly limited use of larger than usual transducer diameters to achieve focal depths greater than $5-6 \mathrm{~cm}$. The small and uniform depths are not inconsistent with a recent study of distances from the midline of the fetal skull and abdomen to the skin (Ragozzino et al. 1986). In that study, the mid-fetal to skin distances ranged from approximately $6 \mathrm{~cm}$ at 7 weeks to $8.4 \mathrm{~cm}$ at 38 weeks. Those distances divided by the maternal AP thickness were $0.3 \pm$ a standard deviation of 0.06 , independent of gestational age.

Given that the purpose of the study by Ragozzino et al. (1986), was estimation of $x$-ray doses to the fetus, it was most appropriate to consider the most probable (mean) fetal distances and attenuation as a function of some known parameter such as maternal AP thickness or weight. The same would be true for ultrasound exposure estimates if the suspected bioeffects mechanism were a low dose effect, as in $\mathrm{x}$-rays, where the probability of the effect is small and increases approximately linearly with exposure. Such might be the case with hypothetical, high intensity, low frequency (e.g., $0.5-2 \mathrm{MHz}$, ultrasound systems) if the pulse durations and peak pressures were well above the cavitation threshold in the absence of attenuation and in the rare presence of cavitation nuclei. Then the probability of damage might depend linearly on the overlying attenuation and a mean attenuation would be appropriate. A more realistic concern, however, are design and use guidelines to avoid a presumed threshold phenomenon, such as hyperthermia. In this situation, worst case analyses are more appropriate.

\section{SUMMARY}

The distribution of minimum thicknesses by tissues overlying the fetus have been measured between 15 and 20 weeks gestation, with an empty maternal bladder technique typical of amniocentesis examinations. These thicknesses and the conservatively computed attenuation of ultrasound are small compared with most earlier estimates. In the worst cases, the calculated attenuation at $3.5 \mathrm{MHz}$ reduces the intensities in the proximal fetal tissues by just under a factor of two, compared with ultrasound intensities measured in water under conditions of linear ultra- sound propagation. While these results reveal cases of less reduction in exposure to the fetus by overlying tissues than previously assumed, it is worth noting that some solid data has appeared documenting the short fetal exposure times in routine obstetrical imaging (Andrews et al. 1987).

Additional detail in the thickness of abdominal wall structures was included here compared with earlier studies. The thickness of these tissue layers overlying the 15-20 week fetus were found to correlate well with maternal weight. The linear regression of maternal subcutaneous fat thickness along the minimum tissue path ranged from $0.8 \mathrm{~cm}$ at $48 \mathrm{~kg}$ to 2.2 $\mathrm{cm}$ at $82 \mathrm{~kg}$. Because of refraction in the low speed of sound fat, such large path lengths through fat can have significant effects on beam focusing with all scanners and on lateral distance measurements with sector scanners. The effects are much worse if the fat interfaces are not coplanar.

Information on minimum fetal depths in the second and third trimesters is provided for comparison with transducer transmitted focal lengths. It is notable that the magnitude and range of fetal depths is relatively small.

In using this information for a worst case analysis of second trimester exposures with an ultrasound system, that focal point of the system would normally be considered which produced the highest intensity and lay beyond $1.7 \mathrm{~cm}$. Again, considering the worst case, that focal point would be considered as lying at the surface of the fetus after ultrasound passage through the minimum predicted body and uterine walls and an appropriate amount of amniotic fluid.

Acknowledgements-This work was supported in part from the PHS Grant 5R01 HD17243, National Institute for Human Growth and Development. Most of the third trimester fetal depth measurements were performed by sonographers, Athena Madonis, RDMS, Terri Marks, RDMS, and Kathy Absalom, RDMS. Ms. Margery Rudd performed patient and data management, Charles Meyer, Ph.D., provided major statistical and other advice and support. Drs. Dietrich Roloff, William Martel, Terry Silver, William Rayburn, Caroline Blane, and Alan Compton helped establish and conduct the fetal maturity project which included this study.

A critical review by George Kossoff was helpful, particularly regarding not separating preperitoneal fascia and abdominal muscle. The journal reviewers helped clarify the manuscript.

\section{REFERENCES}

Andrews, M.; Webster, M.; Fleming, J. E. E.; McNay, M. B. Ultrasound exposure time in routine obstetrical scanning. Br. J. Obstet. Gynaecol. 94:843-846; 1987.

Carson, P. L. Medical ultrasound fields and exposure measurements. In Proceedings Twenty-Second Annual Meeting of NCRP; 1986 April 1-2; NCRP, Bethesda, MD; 1988:308-328.

Dines, K. A.; Sheets, P. W.; Brink, J. A.; et al. High frequency ultrasonic imaging of skin: experimental results. Ultrason. Imaging 6:408-434; 1984.

Duck, F. A.; Perkins, M. A. Amplitude-dependent losses in ultra- 
sound exposure measurement. IEEE Trans. Ultrasonics Ferroelectrics and Frequency Control 35:232-241; 1988.

Gardner, E. S. Testing a regression model. Lotus 3:50-57; 1987.

Hall, A. J. An investigation into certain aspects of the safety of diagnostic ultrasound. Masters Thesis, University of Glasgow. Also presented at 2 nd World Congress on Ultrasonics in Med., Rotterdam, June 4-8, 1973.

International Commission on Radiologic Protection. Report of the Task Group on Reference Man. Task Group of Committee 2 of the International Commission on Radiologic Protection. ICRP Publ. 23. Pergamon Press, NY; 1975.

Nakaima, N.; Aoyama, H.; Oka, M. J. Supplementary study on the ultrasonic absorption of human soft tissues. J. Wakayama Med. Soc. $27: 107-114 ; 1976$

National Council on Radiation Protection. Biological Effects of Ultrasound; Mechanisms and Clinical Implications. NCRP Report No. 74, p. 39. National Council on Radiation Protection and Measurement, Bethesda, MD; 1983.

Pohlhammer, J. D.; O'Brien, W. D. The relationship between ultrasonic attenuation and speed in tissues and the constituents: water, collagen, protein and fat. In: Fullerton, G. D.; Zagzebski,
J. A., eds. Tissue imaging and characterization with computerized tomography and ultrasound. AAPM Technical Monograph No. 6. New York: Amer. Assoc. Physicists in Med.; 1980:409-435.

Ragozzino, M. W.; Breckle, R.; Hill, L. M.; Gray, J. E. Average fetal depth in utero: data for estimation of fetal absorbed radiation dose. Radiology 158:513-515; 1986.

Smith, S. W.; Stewart, H. F.; Jenkins, D. P. A plane layered model to estimate in situ ultrasound exposures. Ultrasonics 23:31-40; 1985.

Sokal, R. R.; Rohlf, F. J. Biometry: the principles and practice of statistics in biological research. 2nd ed. New York: W. M. Freeman and Co.; 1981: chap. 14 and 16.

Soothill, P. W.; Nicolaides, K. H.; Rodeck, C. H.; Campbell, J. Amniotic fluid and fetal tissues are not heated by obstetric ultrasound scanning. Br. J. Obstet. Gynaecol. 94:675-677; 1987.

Stewart, H. F.; Stratmeyer, M. E., editors. An overview of ultrasound: theory, measurement, medical applications and biological effects. Health and Human Services Publication (FDA) 82-8190. Washington, DC: U.S. Government Printing Office; 1982. 